\title{
Use of tree cavities by Indian vertebrates: status of research, knowledge gaps and future conservation perspectives
}

\author{
Bharati Patel $^{1,2,3, *}$, Sreejith Sivaraman ${ }^{1,2}$ and Peroth Balakrishanan ${ }^{1,2}$ \\ ${ }^{1}$ Kerala Forest Research Institute (KFRI), Thrissur 680 653, India \\ ${ }^{2}$ Jawaharlal Nehru Tropical Botanic Garden and Research Institute (JNTBGRI), Thiruvananthapuram 695 562, India \\ ${ }^{3}$ Institute of Forest Biodiversity, Hyderabad 500 100, India
}

Tree cavities play a key role in the structure and functioning of forest ecosystems. Though they host rich and specialized assemblages of numerous vertebrate and invertebrate species, they have received limited research attention in India as well as in tropics. We collated information on cavity using vertebrates of India from the available literature and various databases. Overall, 254 relevant references were found with information about tree and/or cavity characteristics and use for 517 species, which is about $18.4 \%$ of terrestrial vertebrate species of India. Among the 517 species, $\mathbf{4 3 . 9 \%}$ were birds, followed by reptiles $(30.8 \%)$, mammals $(17.6 \%)$ and amphibians $(7.7 \%)$, and the majority of them are rare, elusive and nocturnal species restricted to different regions/habitats. About $80 \%$ of the species are secondary users. Majority of the species use tree cavities as breeding sites $(32.7 \%)$, and another $7.4 \%$ use them as roost, den or hibernation sites. Our analysis also shows that vertebrates use cavities with various characteristics in a wide variety of tree species. We have identified important gaps in research on cavity using vertebrates and cavity-trees. We have also emphasized the need for highly focused long-term studies on habitat interactions to elucidate species level requirements to plan habitat management strategies for the conservation of cavity using vertebrates and their cavity-trees.

Keywords: Cavity-trees, ecological networks, tree cavity, tree-microhabitat, tropical forests, vertebrates.

TROPICAL forests are the most biologically diverse and ecologically complex of all terrestrial ecosystems because of the presence of a wide array of microhabitats across the forest strata. Some of these microhabitats are highly specialized like montane ridges ${ }^{1}$, ant nests ${ }^{2}$, coarse woody debris $^{3}$ and tree cavities ${ }^{4,5}$. The unique thermoregulation characteristics and microclimate $e^{6,7}$ of these microhabitats facilitate specific usage by dependent fauna ${ }^{8,9}$. Among these, tree cavities (hereafter, cavities) are of prime importance, because studies made so far have showed

*For correspondence. (e-mail: bharati.pate109@gmail.com) that cavities provide habitats to a large number of vertebrates and invertebrates ${ }^{10}$. Cavity using species, like bats, hornbills, woodpeckers, civets, etc. ${ }^{11}$ are well known ecosystem service providers and play key role in pollination $^{12}$, seed dispersal ${ }^{13}$ and pest control ${ }^{14}$. Therefore, cavities and cavity-bearing tree species have become a key target for conservation management. Nowadays, such microhabitats have also received much attention in global research not only because of the unique biodiversity they hold, but also as key indicators of ecosystem health ${ }^{15-17}$.

Cavity users (hereafter users) can be divided into two groups $^{18}$ : (i) Primary cavity users (primary users) species that excavate their own cavities. The primary users can be further divided into two subgroups - strong excavators and weak excavators. Strong excavators are large bird species which excavate cavities on trees such as woodpeckers. Weak excavators are species that use/ modify existing cavities or excavate their own cavities. They are less adapted for excavation such as nuthatches ${ }^{18}$. (ii) Secondary cavity users (secondary users) - species that use holes excavated by primary users or formed naturally on stems and branches such as bats, and parrots. The dependent species use them as site for foraging, shelter, roosting, denning and nesting (Figure 1$)^{19}$.

Cavities are critical resources for many animal species, including mammals ${ }^{20}$, birds ${ }^{21}$, amphibians ${ }^{22}$, reptiles ${ }^{23}$ and several invertebrates ${ }^{24,25}$. In forests worldwide, cavity availability can limit populations of approximately $18.1 \%$ ( $n=1878$ ) of the bird species. It is reported that, $19 \%$ $(n=355)$ of the global cavity using birds are strong excavators, $7 \%(n=126)$ are weak excavators and $73 \%$ $(n=1357)$ are secondary users ${ }^{26}$. Also, the primary excavators have been found to be strong indicators of richness of bird species (both users and non-users) ${ }^{27}$. As per the available information on secondary users, other than birds, 350 mammal species in Atlantic Neotropics ${ }^{10}$; and 86 mammals, 78 reptiles and 29 amphibians in Australia ${ }^{19}$ depend on cavities. In Canadian forests, $30 \%$ of vertebrates depend on cavities for nesting and roosting ${ }^{18}$. It is estimated that $13 \%$ of global cavity using birds ${ }^{26}$, fall under various threat categories. Conservation of these vertebrate communities may depend critically on understanding their 

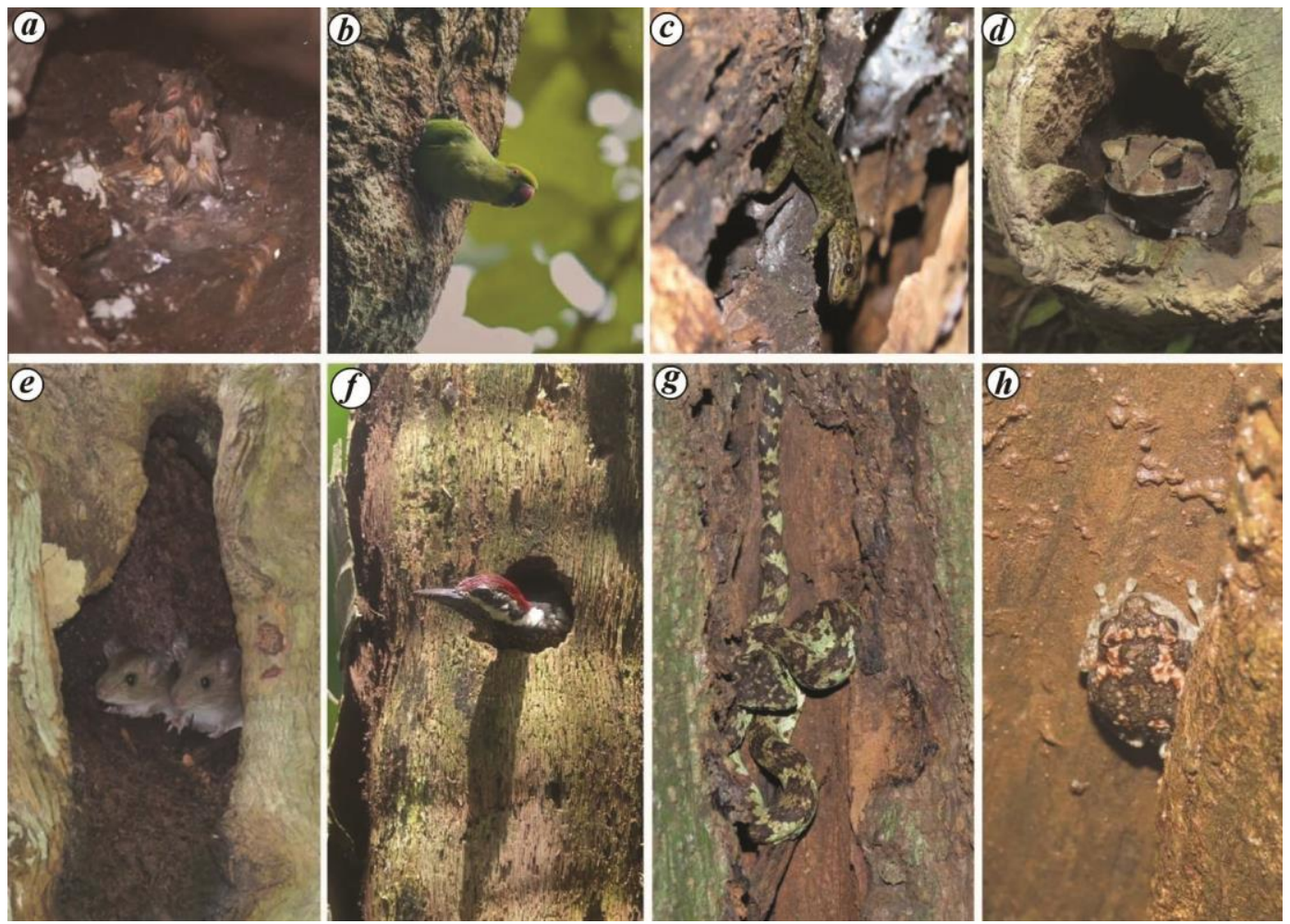

Figure 1. Representative denizens of tree cavities: $\boldsymbol{a}$, Megaderma spasma (Lesser False Vampire Bat); $\boldsymbol{b}$, Mus sp (Mouse); $\boldsymbol{c}$, Psittacula krameri (Rose-ringed Parakeet); d, Dinopium benghalense (Lesser golden-backed Woodpecker); $\boldsymbol{e}$, Cnemaspis sp. (Lizard); $\boldsymbol{f}$, Trimeresurus malabaricus (Malabar Pit Viper); $\boldsymbol{g}$, Duttaphrynus parietalis (Indian Toad); $\boldsymbol{h}$, Uperodon taprobanicus (Painted Kaloula).

habitat interactions highlighting the key relationship between cavity producers and users ${ }^{10,28}$.

Extensive studies on cavities as important habitat components are available from temperate regions ${ }^{29,30}$, and have provided commendable inputs for the conservation management of species and communities. The most studied cavity using vertebrates across the globe are birds, while studies on cavity using mammals are largely restricted to Australia and North America ${ }^{11,31,32}$. Global occurrences of cavities are 2.5 times more in the tropics compared to the temperate ${ }^{33}$, but this is reverse in the case of snag availability. Deadwood used as cavity substrate is subjected to faster decay in tropics ${ }^{32}$. Even the Neotropical and Oriental regions have highest richness of cavity using birds, 678 and 453 species respectively ${ }^{26}$, probably because of the abundance of cavities and cavity excavators $^{33}$. Yet the percentage of studies on cavities as habitat and information on their dependents are much higher from temperate (Europe and North America) compared to the tropical climate forests ${ }^{34}$. On the other hand, studies on the cavities, their abundance, formation and persistence, cavity-dependent vertebrates and their nature of interaction with cavities are quite limited in the tropics $^{16}$.

The earliest studies on cavity users in India ${ }^{35,36}$ were on birds, and they together reported cavity descriptions of about 10 species. Detailed studies on cavity users are limited to few primary users, including woodpeckers ${ }^{37}$, barbets $^{38}$, trogon ${ }^{39}$, and secondary users including hornbills $^{40}$ and owlets ${ }^{41}$. Although a comprehensive estimate of cavity using vertebrates other than birds in India is not available, some extensive studies and information from systematic and anecdotal reports show obligate or facultative use of cavities by different groups, including the more elusive species such as civets, rodents, martens, bats and tree frogs ${ }^{22,42-45}$. Accounting for the vast diversity of vertebrates, complexity of ecosystems and their current threat in India, studies on cavity use would provide important insights into the role of this critical microhabitat in the sustenance of fauna and practical implications for the conservation management of tropical forests. We have tried to fill the information gap on cavity using vertebrates of India. This might help to identify the lacunae and guide future research to obtain sufficient knowledge to characterize cavities used by vertebrates, and recognize tree cavities as indicators of biological diversity in tropical forests of India.

This review is an attempt to: (i) list the cavity using vertebrates in India; (ii) collate the information available on cavity using vertebrates, and (iii) identify the knowledge gaps considering cavity usage as a critical habitat resource. 


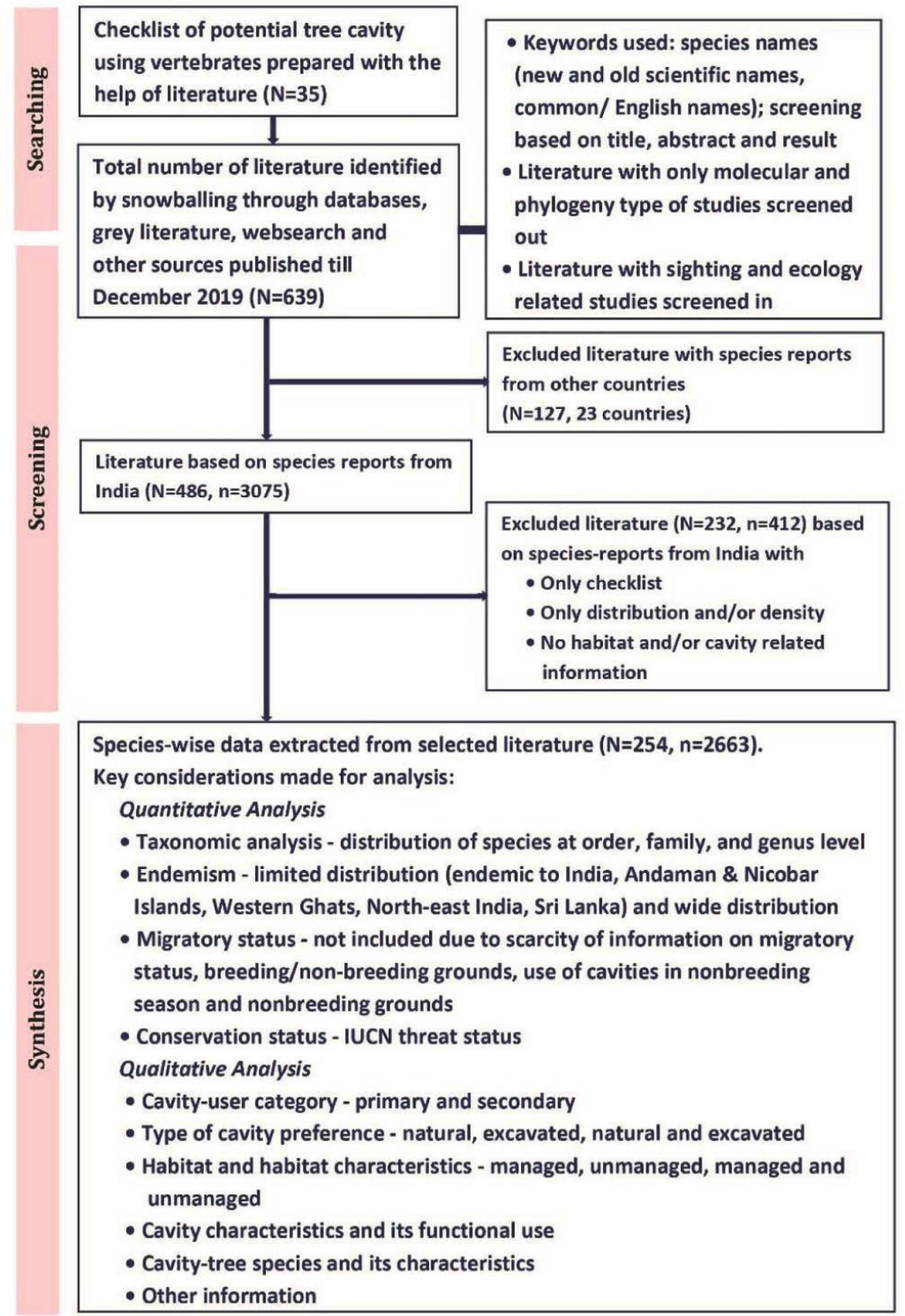

Figure 2. Flow chart of method followed to search, screen and synthesize references to prepare this review. $N=$ Number of references, $n=$ Number of species reports.

\section{Methods}

A checklist of potential cavity using vertebrate species belonging to Mammalia, Aves, Reptilia and Amphibia of India was prepared based on the available checklists, natural history information, and recent species descriptions from various literature (Figure 2, Supplementary Material 1). Initially, we hypothetically considered all the arboreal and strictly arboreal species as cavity users. We screened the literature (published till December 2019) based on title, abstract and results. We ignored the journal metrics and other similar ratings to trace all relevant information. For the final checklist of potential cavity users, articles with information on sightings, behaviour observations, habitat selection, breeding biology, etc. were included for possible insight on cavity use. In addi- tion, articles from other countries where the enlisted species have been reported to breed were also included. This was done by observing the limited useful published articles from India. However, to analyse the quantity and quality of information on the enlisted species, we used the studies and reports from India only.

The information from selected references was extracted species-wise for analysis, henceforth termed as speciesreports in this review. Therefore, the number of references is less than the number of species-reports as some references contained information on more than one species. The key considerations made to analyse the data for enlisted species are mentioned in Figure 1. The International Union for Conservation of Nature (IUCN) database was referred for the threat and conservation status ${ }^{46}$. The species were segregated to see their preference for cavities - excavated 
or natural, as they vary in terms of size, depths, entrance dimensions, substrate status (live, decaying, dead), microclimate, persistence (longevity) in case of species with high nest fidelity, etc. We broadly grouped the reported cavity uses into obligate and facultative use. Obligate uses included breeding, den, day rest site, roost, hibernation which may have an impact on survival and population status of the user. Facultative uses included foraging sites, hiding, refuge, perching and any other opportunistic use.

The quality of information was analysed based on the following variables: (1) distribution; (2) habitat characteristics and (3) cavity characteristics, if available. For this analysis we considered all the references with information on at least one of the cavity related variables, and in some cases included single sighting/opportunistic reports of the enlisted species with scarce reports to record the overall pattern of information. We used only the following 32 variables to generate heatmap as visual representation to assess the quantity and quality of information available - (1) type of habitat used (type_habitat), (2) altitude (altitude), (3) use of managed habitat (managed), (4) use of unmanaged habitat (unmanaged), (5) use of managed and unmanaged habitats (managed. unmanaged), (6) tree species used (tree_species), (7) height of cavity-trees (tree_height), (8) canopy cover in habitat (canopy_ cover), (9) height of canopy in habitat (canopy_height), (10) density of trees in habitat (tree_density), (11) diameter of cavity tree at breast height (tree_dbh), (12) shrub cover (shrub_cover), (13) herb cover (herb_cover), (14) vitality of cavity-tree (tree_vital), (15) distance of cavitytree from road (distance_road), (16) distance of cavitytree from waterbody (distance_water), (17) density of cavity-tree/s (cavity_tree_density), (18) presence/absence of climbers/liana (climber), (19) presence/absence of deadwood (deadwood), (20) cavity substrate (cavity_ structure), (21) type of cavity use (type_use), (22) cavity reuse (cavity_re_use), (23) cavity origin (cavity_origin), (24) height of cavity (cavity_height), (25) diameter of tree at cavity height (diameter_cavity_height), (26) depth of cavity (cavity_depth), (27) cavity entrance length (cavity_enter_length), (28) cavity entrance width (cavity_ enter_width), (29) shape of cavity entrance (cavity_shape), (30) orientation of cavity (orientation), (31) sequential use of cavity (cavity_seq_use), (32) number of cavities used (cavity_count). We assigned the binary weight variables (presence $=1$, absence $=0$ ) for each species report, and did the summation of all the reports at order level for each vertebrate group to get the final value/ variable. These values were used to generate the heatmap. An attempt was made to check the clustering of variables based on the information per report. We used expression clustering based on Euclidean distance, and is represented as a dendrogram. All data analysis and preparation of graphical representations were conducted in Microsoft Excel, and eulerr ${ }^{47}$ and ComplexHeatmap ${ }^{48}$ packages in $\mathrm{R}$ programme.

\section{Results and discussion}

\section{Quantitative information on cavity using vertebrates}

Quantum of literature: We accounted all the available references for assessing the quantum of literature, however, we excluded the overlapping references for assessing, and preferring the published research paper over other forms of literature. Details of the number of species and species-reports considered are shown in Figure 2. Research papers $(58.4 \%)$ and short communications $(19.1 \%)$ formed major information sources. Other relevant and voluminous information resources included the websites/ databases $(7.2 \%)$, and technical reports $(6.6 \%)$. Thesis/ dissertations $(3.1 \%)$ and books/book chapters $(3.1 \%)$ also carried information on cavity using species (Supplementary Material 1). Rest of the literature published as newsletter articles, popular articles, conference and seminar proceedings were merged under 'Others' category $(2.5 \%)$. The short communications and miscellaneous reports provided the only available information for more than 20 species of birds ${ }^{49-51}$.

Diversity of tree-cavity using vertebrates: As per available information, $18.5 \%$ of the 2804 vertebrate species reported from India depended on cavities as a habitat resource (species list updated till April 2020). We identified 517 vertebrate species as cavity users; among these, most dominant were birds $(44.1 \%)$, followed by reptiles $(30.8 \%)$, mammals $(17.6 \%)$, and least are amphibians (7.7\%) (Supplementary Material 2). Overall, $21.0 \%$ of the mammals, $17.2 \%$ birds, $26.1 \%$ reptiles and $9.0 \%$ amphibians reported from India use cavities (Figure 3). Data on cavity use at the global level is not available for mammals, reptiles and amphibians, but the ratio of cavity using birds in India follows the global pattern which reports at least $18.1 \%$ of bird species across the globe as cavity users ${ }^{26}$. The current estimates of cavity use by amphibians will be an underestimate for sure, as they are known for their high sensitivity and specialized habitat requirements. Their elusive nature and/or lack of targeted studies on their habitat-use may be the major reasons for this low number compared to the high probability. Nearly $77.6 \%$ Indian cavity users showed limited distribution, and $19.1 \%$ of the listed species showed at least some level of endemism (Figure 4). Among the cavity users, majority of amphibians $(72.5 \%)$ and reptiles $(61.6 \%)$ had restricted distribution range while this number was less for mammals $(31.5 \%)$ and birds $(23.4 \%)$. Also, $\sim 10 \%$ of the cavity using birds and $18 \%$ of mammals showed some level of endemism.

Taxonomic diversity of cavity using vertebrates: Taxonomically, the most diverse users were birds, followed by mammals, reptiles and the least diverse group was 
amphibians. The 517 species listed belonged to 18 orders in 4 classes namely, Mammalia (5 orders), Aves (11), Reptilia and Amphibia (1 each). A high taxonomic diversity was observed within the groups (Figure 5) which indicated morphological and behavioural diversity in the users. Highest number of species were observed in Aves (227 species), followed by Reptilia (159), Mammalia

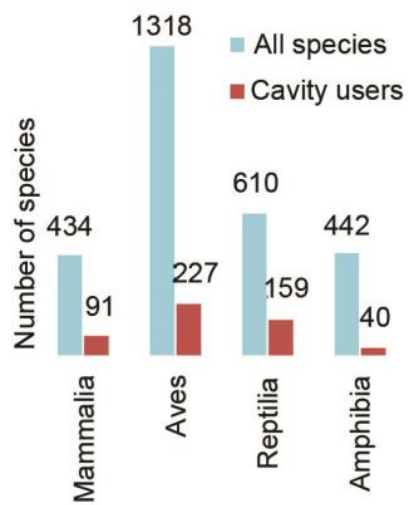

Figure 3. Number of tree cavity using vertebrates reported in India.

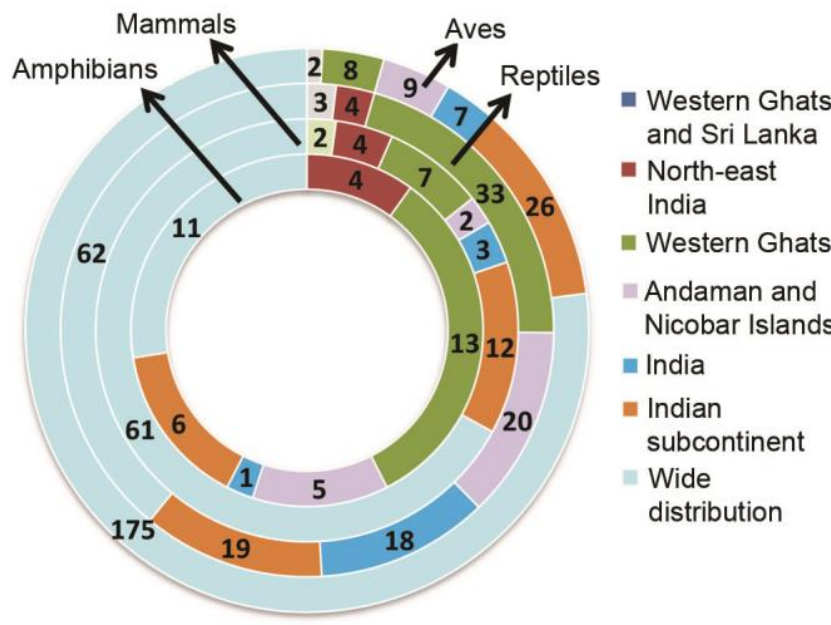

Figure 4. Geographic distribution of tree cavity users of India.

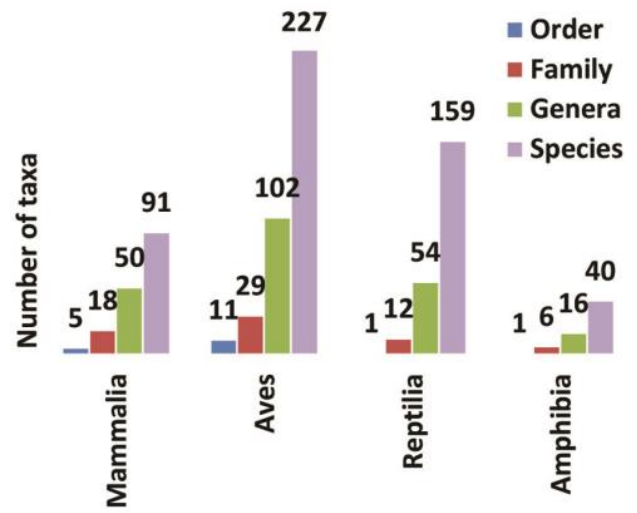

Figure 5. Taxonomic distribution of tree cavity users.
(91) and Amphibia (40). Several factors such as arboreality, morphology, physiology and reproductive traits of the animals are known to have significant roles in the creation and usage; and selection of type and size of cavities $^{5,10,18}$

Birds: Cavity using birds from India belonged to 29 families including 4 families (Picidae, Megalaimidae, Sittidae and Trogonidae; 56 species) that exclusively depended on cavities. Though members of the orders Galliformes, Phaethontiformes, Columbiformes, Gruiformes are known to use cavities in other regions, none reported from India ${ }^{26}$. Cavity using birds included strong excavators (35 species of Picidae) and weak excavators (20 species of Megalaimidae, Sittidae and Trogonidae). Primary excavators act as key ecosystem engineers by providing cavities to non-excavating species after their use $^{52,53}$. For example, cavities excavated by woodpeckers are used by several other species of birds ${ }^{41,51}$ and small mammals $^{44}$ for breeding or roosting. Globally, birds of 16 orders have been reported to use cavities, and in India we have listed species from 11 orders. Passeriformes (perching birds) is one of the major users globally; at least 586 species of this group are believed to make facultative or obligatory use of cavities ${ }^{26}$. In India too, Passeriformes with 96 species, representing mostly the secondary users, dominate. Among the families, Muscicapidae (flycatchers), in Passeriformes has the largest number of secondary users (37 species) in India. It is also the least known group in terms of breeding biology and other ecological factors influencing their life history strategies. These birds may specialize to a combination of external (such as cavity height, entrance dimension, orientation), and the internal factors (such as temperature, presence of decay agents, decay stage), and influence the cavity selection by birds. An international study on the cavity using flycatchers showed the influence of interspecific cavity competition on body size, migration and clutch size; larger body size increases the chances of winning a cavity and have maximum clutch size ${ }^{7}$. Cavity use is also associated with breeding migration to high latitudes, postulating former as an adaptive behaviour of that group ${ }^{54}$. Along with suitable nesting trees, availability of abundant food resources is also an influencing factor for abundance of species, especially in forest edges ${ }^{55,56}$.

Mammals: Approximately $80 \%$ of the cavity dependent mammal species are distributed in two orders, Chiroptera (34 species) constituting the bats, and Rodentia (40) constituting squirrels, rats and mice. These include small insectivorous bats such as lesser woolly horseshoe bat Rhinolophus beddomei, arboreal murids such as Indian long tailed tree mouse Vandeleuria oleracea, and flying squirrels such as Indian giant flying squirrel Petaurista philippensis. These animals spend a considerable part of their life inside the cavities in both breeding and nonbreeding seasons. 
Reptiles: The single order Squamata includes all the cavity using reptiles. The major families include the colubrid snakes Colubridae (44 species), geckos Geckonidae (38) and lizards Agamidae (28). Some of the key users include Southern flying lizard Draco dussumieri, ornate flying snake Chrysopelea ornata, coastal day gecko Cnemaspis littoralis, and common Indian monitor lizard Varanus bengalensis. Given the recent trends in the reptile taxonomy with descriptions of a large number of new species, a greater number of cavity using reptiles may enter the list in future.

Amphibians: The 40 species of cavity using amphibians known till date are distributed in 6 families and $67.5 \%$ of the species (27) belong to the family Rhacophoridae. They are also called 'bush frogs', and known to inhabit trees at the time of breeding to utilize the water filled in hollow stem and branches of trees. The frogs of this group are also called as 'treefrogs' and include the genera Raorchestes, Rhacophorus, Theloderma and Philautus as cavity users. Another major group of cavity using frogs is from the family Microhylidae (6 species) and include Uperodon sp. More number of species is expected to enter this list as the research on microhabitat use for this group advances.

Conservation status of tree-cavity using vertebrates: Analysis of the present study showed that $9.3 \%$ of the users belonged to globally threatened categories; of these $1.4 \%$ are critically endangered, $3.5 \%$ endangered and $4.4 \%$ vulnerable (Figure 6). Group-wise, highest number of species in these categories were that of amphibians (32.5\%) followed by mammals $(13.2 \%)$. Among reptiles, $6.9 \%$ species came under the threatened categories, and $5.7 \%$ of birds are threatened. On the other hand, for about $20.5 \%$ of the users, either information was not sufficient or their conservation status was yet to be assessed. Since

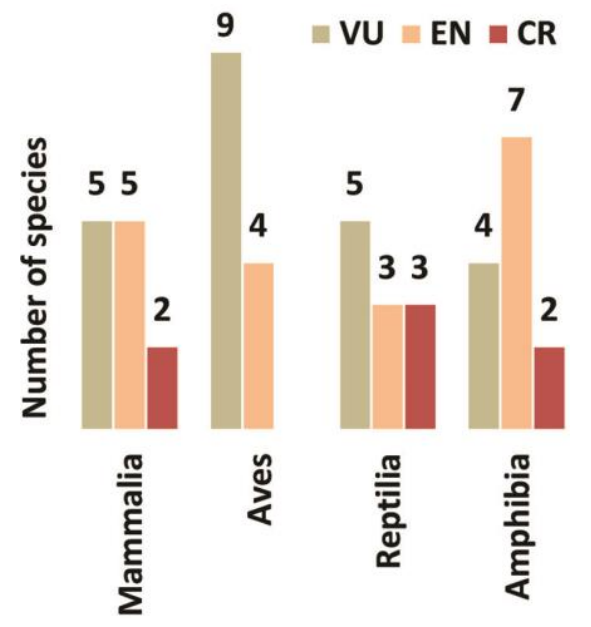

Figure 6. Tree cavity users in IUCN threatened categories. CR, Critically endangered; EN, Endangered; VU, Vulnerable. information on the availability, structural and microclimatic characteristics of microhabitats are critical for identifying the bottlenecks and planning conservation strategies for threatened species, targeted studies on the microhabitat associations of such species should be a research priority.

Primary versus secondary cavity users: Among the 517 tree-cavity users, 54 species $(10.4 \%)$ were primary and $463(89.6 \%)$ were secondary users which depended on primary excavators and natural cavities. Only $7.4 \%$ of the primary users were endemic to India ${ }^{45,57}$ and included species such as Andaman woodpecker Dryocopus hodgei, scaly-bellied woodpecker Picus viridanus and Malabar Trogon Harpactes fasciatus. Among the secondary users, $23 \%$ of the species from all the vertebrate groups showed various levels of endemism (regional to country level). There are reports on secondary users that depend on excavations of the primary users or natural formations for the availability of these habitat structures ${ }^{35-37}$, but for a limited number of species. There are also reports of small bats using boreholes created by insects such as beetles ${ }^{58}$. The dependency of about $42.1 \%$ of secondary users, including a large number of endemics demands the crucial presence of primary excavators and availability of natural cavities in their distribution range (Figure 7). These user communities in an ecosystem interact through the creation of and competition for cavities as nesting and roosting sites. The pattern of these interactions in a community often described using a network approach has

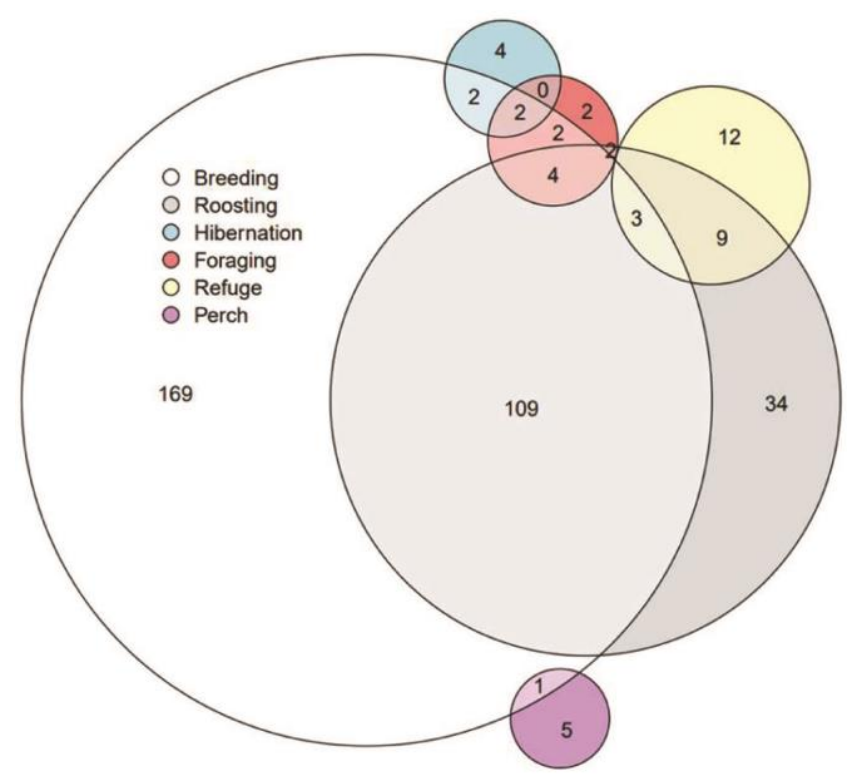

Figure 7. Functional use of tree cavities by vertebrates: size of the circles and numbers represent the counts of species; intersections of the circles represent more than one type of use by respective species; For example, out of the 4 species using cavity for hibernation, 2 species use them for breeding and 2 species use it for foraging also (intersection between hibernation and breeding). 
become an important conservation tool ${ }^{18,30}$. However, such information at a community level for primary and secondary cavity users are not available for the Indian vertebrates.

Functional use and preferred cavity types: Available information indicated that $51.4 \%$ users depended on cavities for breeding, $23.8 \%$ roost in the dark holes, $9.3 \%$ used them exclusively as den or day rest sites, and $0.8 \%$ species used it to hibernate (Figure 7). The obligate uses are often overlapping such as in case of bats and rodents, wherein the same species may use the cavities for breeding as well as roosting ${ }^{38,59}$. The characteristic features of cavities like microclimate ${ }^{7,9}$ and predator avoidance ${ }^{43,60}$ could be the reasons for exclusive use of these structures by several species.

In India, facultative use is reported for a few species and is based on the reported use of other structures such as holes in mud-walls and rock crevices, apart from cavities. A brief account of the type of cavity and dependency of the enlisted species is provided in Supplementary Material 2. The species reports suggested facultative use of cavities by $8.7 \%$ of the enlisted species including brown fish owl Ketupa zeylonensis ${ }^{61}$, Yellow throated Marten flavigula ${ }^{62}$, etc. Overall, the specific use by $45.8 \%$ species was missing from the species reports, and majority of this was for the reptiles $(82.7 \%)$. Despite these lacunae, these species were included in the final list by observing the reports on potential cavity use, characteristics of the family or genus, and reports/photographs on arboreal habit of the groups such as Rhacophoridae ${ }^{63}$, and forest and garden lizards Calotes spp. ${ }^{64}$.

We also analysed the cavity preference of the enlisted species along with the type of dependency (Figure 8). The primary users such as nuthatches, Sittidae family, often modify natural cavities by even using masonry work or excavations of other primary users ${ }^{65}$. The Great Slaty woodpecker Mulleripicus pulverulentus and Great barbet

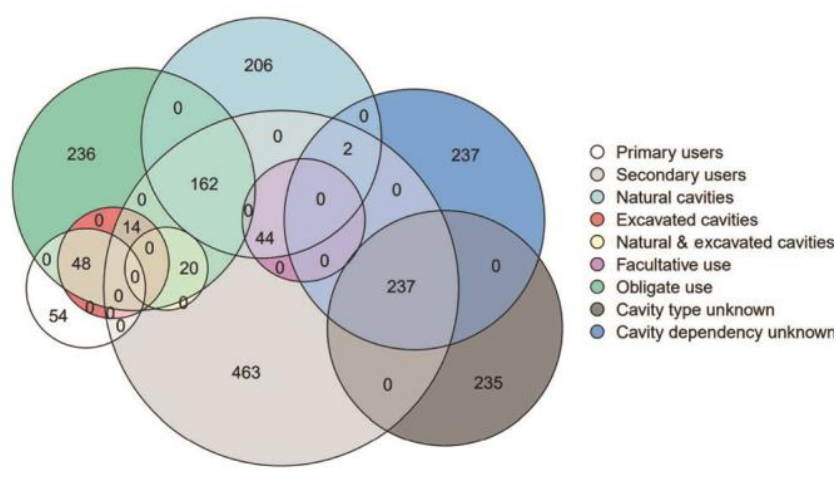

Figure 8. Cavity preference and dependency of vertebrates: size of the circles represent the number of species in mapped categories and intersections represent more than one category for respective species counts; for example, 20 secondary users have obligate dependency on both natural and excavated cavities.
Psilopogon virens reuse their old cavities ${ }^{66}$. About 24 bird species seen in India exclusively depend on excavators for cavities. They use only excavated holes when vacated or win in competition with the excavators by usurpation. The excavated cavity users include mammals such as Indian bush rat Golunds ellioti ${ }^{67}$ which prefer abandoned excavated cavities. The competition for excavated cavities is reduced by the availability of natural cavities which are preferred by majority of secondary users (206 species). There is a huge gap in knowledge on the type of cavity preferred by approximately $45.5 \%$ of secondary users, mostly reptiles and mammals.

The available information is insufficient or limited to interpret the gradient of cavity-use by both reptiles and amphibians. The arboreal lizards such as Tokay gecko Gekko gecko have been reported to use cavities as well as ground for breeding ${ }^{68}$. The monitor lizard Varanus bengalensis use cavities in both breeding and non-breeding seasons ${ }^{23}$, but such reports ${ }^{69,70}$ are rare from India. The tree frogs are among the most arboreal amphibian species, but the benefits of their arboreal habits are largely unknown. Further information on the use of cavities by amphibians is scarce, probably due to their elusive nature, rarity and lack of focussed studies. Moreover, a large number of species from these groups are described fairly recently and so lack information on their life histories.

\section{Quality of information on cavity use}

The quality of information available on the distribution, habitat, and cavity characteristics of the species belonged to the 16 out of the 18 cavity using vertebrate orders from India, and is represented as a heatmap (Figure 9). Although two orders, namely Phaethontiformes (tropicbirds such as white-tailed tropicbird Phaethon lepturus) and Pholidota (pangolins) of Aves and Mammalia respectively, are known as cavity users ${ }^{26}$, no information is available about them from India. Majority of the information on cavity users is from managed habitats (851 reports) such as plantations, and the remaining are from unmanaged habitats (664 reports) such as natural forests or protected areas. This information also echo the immense need for active conservation efforts in the species rich areas out of protected area boundaries. For the majority of the orders, distribution related information is available along with the type of the structures used and dependency, with exceptions being the Anseriformes, Charadriiformes and Scandentia with poor information on these aspects (Figure 9). Detailed information on the habitat characteristics are missing for the majority of the groups, showing the importance of future research on habitat selection. Information on tree species and vitality of the trees (dead or alive) used by cavity users are reported for most of the orders. Cavity characteristics are 


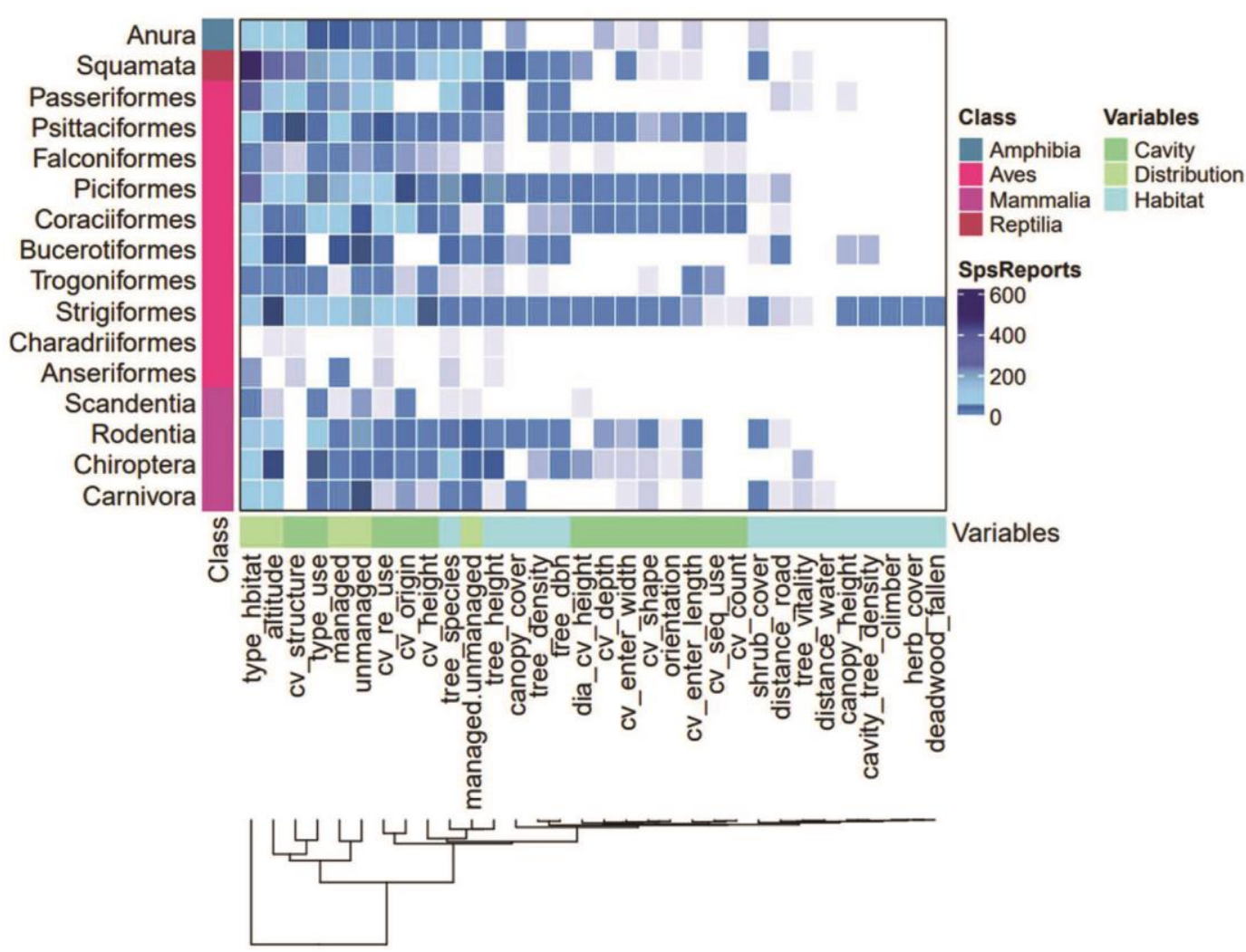

Figure 9. Information on tree cavity using vertebrates from available references: expression heatmap generated from species-report counts, clustering of variables done with euclidean distance (represented as dendrograms). The colour gradient (white to deep blue) indicate the quantity of species-reports, white being no report to deep blue with high counts. The variables have been grouped into three categories - (1) distribution of species, (2) habitat characteristics, (3) cavity characteristics.

reported for selected species belonging to a number of orders such as Piciformes, Strigiformes, Psittaciformes and Chiroptera, but not enough to derive conservation and management strategies if needed in future.

Preference of cavity-trees, their diversity and vitality: Based on the available information, the cavity bearing trees used by each class were grouped taxonomically. Birds used the maximum number of cavity bearing tree species (126 species), followed by mammals (57), reptiles (14) and amphibians (8). High species diversity and relatively higher number of studies on cavity using birds are reflected in these numbers. Though the numbers of cavity using reptiles are more, information on the tree species selection is relatively poor. Moraceae (24), Leguminosae (23 species), Arecaceae (16), Lythraceae (15), Meliaceae (13) were major cavity-tree families used by Indian vertebrates (Figure 10).

The primary users preferred dead and decaying wood softened by fungal fruiting bodies to ease excavation ${ }^{38,71}$. Ten primary users preferred dead trees over live trees, which included pygmy woodpecker Picoides nanus ${ }^{50}$, white-bellied woodpecker Dryocopus javensis ${ }^{36}$ and Malabar trogon Harpactes fasciatus ${ }^{39}$. Barbets (4 spp.) did not show specificity to the vitality of the substrate, but the presence of decayed fungi was the key in site selection ${ }^{47}$. For the primary users, information on the vitality of cavity-trees and substrates were lacking for more than $60 \%$ and $85 \%$ users respectively. Similarly, the preferred substrate vitality was lacking for more than $85 \%$ secondary users. The availability of cavities, both excavated and natural depended on the abundance of suitable trees. Natural cavity formation in trees occurs because of several reasons, including any injury due to biotic and abiotic factors such as termites, lightning, wind or decay in exposed sapwood ${ }^{72}$. The tree species prone to fungal infections and heart-rot with age $\mathrm{e}^{73}$ are preferred substrates for nest or den by many users ${ }^{32,53}$. Other factors which influence the cavity use are the dimensions and microclimate of the cavities ${ }^{29,30}$. However, species level information on such factors in the selection of suitable cavities are needed for majority of vertebrates.

Cavity characteristics - substrate, location and dimension: A descriptive analysis of the key tree and cavity characteristics belonging to three classes has been provided in Supplementary Material 3. Here, reptiles have been excluded due to lack of sufficient data. Detailed information 


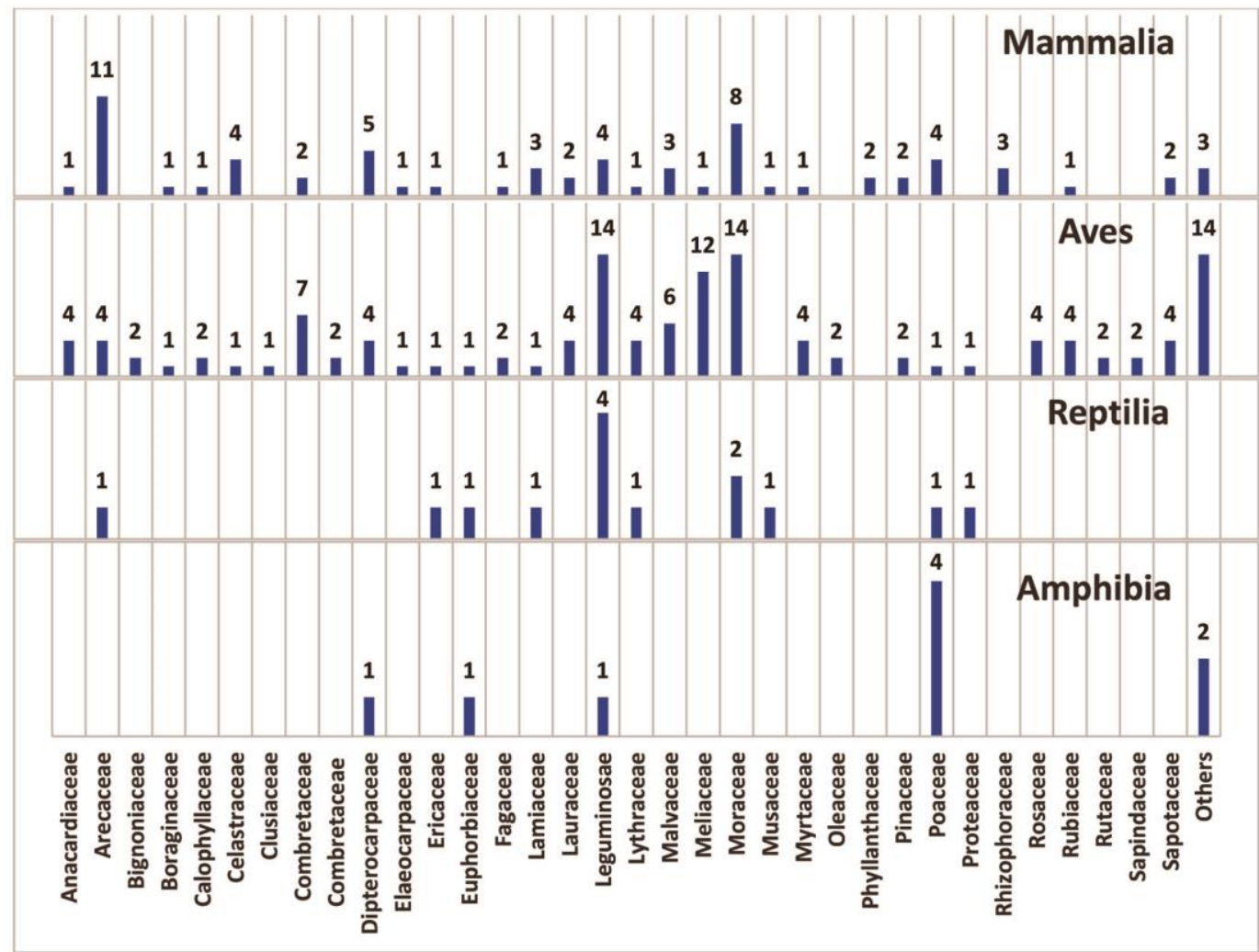

Figure 10. Taxonomic distribution of cavity-trees families used by different vertebrate classes. Others include the families with single use reported for any of the classes. For example, in case of amphibia the value 2 in others represent two families each with single report of use by only amphibians.

about cavity-tree and cavity characteristics of 14 species of mammals were available. Since cavity using mammals varied in size and other life history traits, variations in the cavity preferences were expected and therefore we did not attempt thorough comparison of the cavity characteristics. Similarly, cavity characteristics were available for 32 species of birds, including 17 primary users. The diameter of cavity-trees preferred by primary users were in the range of $0.60-1.05 \mathrm{~m}$, whereas secondary users had a wide preference of $0.24-7.03 \mathrm{~m}$. Barbets, one of the important primary users prefer a medium height range $(0.60$ $14.00 \mathrm{~m}$, rarely above $20 \mathrm{~m}$ ) for excavating cavities, but on dead branches softened by decayed fungi ${ }^{35,36,38}$. Reptiles use a variety of substrates and microhabitats such as large stems or branches, buttresses and fissures, bark ${ }^{74}$, prop roots, lianas ${ }^{75}$, stumps and $\operatorname{logs}$ for breeding and non-breeding activities. The specific use of the cavity is not known for more than $50 \%$ of the enlisted species, and most of the facultative use reported was for basking and perching. The type of substrate and cavity being used diversifies with the body size and species characteristics. Majority of the species-reports highlighted that the reptiles using cavities and other microhabitats preferred lower heights on the trees mainly as hides and refuge sites. Considering the higher numbers of potential cavity users (159 species), red listed and data deficient species, it was clear that the reptiles were the most understudied class in terms of habitat requirements and required considerable research attention. The specific cavity use by amphibians is known for 25 species, while for other species that have been observed in association with the cavities, the dependency could not be distinguished. Cavities filled with rainwater act as ephemeral pools called dendrothelms, and are used for breeding and hiding during day time. Amphibians often prefer natural cavities filled with water at lower heights of 0.30-4.00 m (refs 75 and 76). Majority of cavity use for amphibians has been reported recently from wet-evergreen, evergreen and semi-evergreen forests, and information for a large number of species are lacking to assess their dependency and characteristics of cavities.

\section{Conclusions and future perspectives}

This review is an attempt to list and collate information on cavity using vertebrates of India to identify the research gaps. It revealed that studies on cavities are scarce and most of them are focused on single or threatened higher vertebrate species, with only 251 references having relevant information. About $18 \%$ of terrestrial and arboreal vertebrates of India are cavity users. It includes 
primary users (about 10\%) such as woodpeckers, barbets, trogons and nuthatches and secondary users (90\%) include hornbills, owls, parrots, tits, starlings, some flycatchers, bats, tree squirrels, tree mice, civets and martens. Both these groups are important ecosystem service providers. About $9 \%$ of cavity users are red listed and deserve special conservation concern because of habitat loss or cavity-site loss, which are serious threats to their survival. More than $45 \%$ of the species use cavities as breeding sites, and another $33 \%$ use them either as roosts or den sites. The sequential use and characteristics of the cavities used by the majority of vertebrates are poorly documented. As a community, vertebrates in an ecosystem interact through the creation of and competition for cavities. These connections and interdependencies among cavity using communities are a hierarchy of interconnected tree resources, cavity excavators, and secondary cavity users, which provide a predictive framework for species and ecosystem management. But such knowledge is completely lacking for the tropical forests. There are many potential reasons for these lacunae, the major ones probably being the highly secretive and nocturnal nature of mammals, seasonal changes in the cavity use behaviours of reptiles and amphibians, and lack of studies on breeding site selection of cavity nesting birds for many regions. At present, majority of information available on the cavity use by vertebrates are from the natural history studies and indicates the need for promoting and collating natural history information on the cavity-vertebrate interactions. Another reason for lack of information may be due to the short-term nature of the ecological studies which may not always yield good quantity and quality of data. Therefore, there is a need for long-term studies with standard methods and guidelines to understand the relationships between cavities and their users in the tropical forests.

By providing critical habitat resources to several vertebrates, cavity-trees have been considered as an important parameter in wildlife conservation and forest management. The loss of large old trees is also a recognized concern in many ecosystems worldwide. However, information on the status of large and old trees which carry cavities of the tropical forests of India is scanty. Many plant families characterized by large trees also have a relatively large number of threatened plants. It is a known fact that about $50 \%$ of the cavity nesting trees used by the South Indian hornbills belong to rare, endangered or threatened categories ${ }^{77,78}$. Therefore, any attempt to the conservation and management of the cavity-trees will simultaneously help the protection of several rare and endemic plants. Also, identification of the cavity bearing tree species used by different animals will help to prevent the 'functional extinction' as in the case of loss of several invertebrate species associated with American Chestnut when it was decimated by Chestnut Blight Cryphonectaria parasitica $^{79}$.
Long-term studies to answer many multidisciplinary questions such as - What is the diversity of natural and excavated cavities in different forest types? What type of cavities do the tropical vertebrates need? Which wood traits are responsible for natural formation of cavities? How much time it takes for natural formation of cavities? How long can snags (standing dead tree) stand in a tropical forest to serve as cavity substrate? Which habitats have more primary excavators and which resource components play a role in their abundance? Is there any specific fungi-excavator relationship in the Indian forests? What are the survival rates of natural and excavated cavities? How the cavity using community-webs are structured in different forest types in India?, etc. These questions require answers for planning habitat management strategies for the conservation of cavity using vertebrates and cavity-trees.

1. Kessler, M. and Lehnert, M., Are ridge habitats special sites for endemic plants in tropical montane rain forests? A case study of pteridophytes in Ecuador. Folia Geobot., 2009, 44, 387-398.

2. Tews, J., Brose, U., Grimm, V., Tielbörger, K., Wichmann, M., Schwager, M. and Jeltsch, F., Animal species diversity driven by habitat heterogeneity/diversity: the importance of keystone structures. J. Biogeogr., 2004, 31, 79-92.

3. Bull, E., The value of coarse woody debris to vertebrates in the Pacific Northwest, United States Department of Agriculture (USDA) Forest Service General Technical Report, PSW-GTR181, 2002, pp. 171-178; https://www.fs.fed.us/psw/publications/ documents/psw-gtr181/016_Bull.pdf (accessed on 13 December 2017)

4. Newton, A. C., Forest Ecology and Conservation: A Handbook of Techniques, Oxford University Press, USA, 2010, p. 454.

5. Cockle, K., Martin, K. and Wiebe, K., Selection of nest trees by cavity-nesting birds in the Neotropical Atlantic Forest. Biotropica, 2011, 43, 228-236.

6. Paclík, M. and Weidinger, K., Microclimate of tree cavities during winter nights - implications for roost site selection in birds. Int. J. Biometeorol., 2007, 51, 287-293.

7. Rhodes, B., O'Donnell, C. and Jamieson, I., Microclimate of natural cavity nests and its implications for a threatened secondary-cavitynesting passerine of New Zealand, the South Island Saddleback. The Condor, 2009, 111, 462-469.

8. Kerth, G., Weissmann, K. and Konig, B., Day roost selection in female Bechstein's bats (Myotis bechsteinii): a field experiment to determine the influence of roost temperature. Oecologia, 2001, 126, 1-9.

9. O'Connell, C. and Keppel, G., Deep tree hollows: important refuges from extreme temperatures. Wildl. Biol., 2016, 22, 305310 .

10. Cockle, K., Martin, K. and Wesołowski, T., Woodpeckers, decay, and the future of cavity-nesting vertebrate communities worldwide. Front. Ecol. Environ., 2011, 9, 377-382.

11. Martin, K., Nest webs and woodpecker ecological services: the role of woodpeckers in tree cavity-using wildlife communities in North America. Denisia, 2015, 164, 77-86.

12. Martins, A., Willig, M., Presley, S. and Marinho-Filho, J., Effects of forest height and vertical complexity on abundance and biodiversity of bats in Amazonia. Forest Ecol. Manage., 2017, 391, 427-435.

13. Corlett, R., Frugivory and seed dispersal by vertebrates in tropical and subtropical Asia: an update. Glob. Ecol. Conserv., 2007, 26, 3005-3035. 
14. Brockerhoff, E. et al., Forest biodiversity, ecosystem functioning and the provision of ecosystem services. Biodivers. Conserv., 2017, 26, 3005-3035.

15. Lindenmayer, D., Margules, C. and Botkin, D., Indicators of biodiversity for ecologically sustainable forest management. Conserv. Biol., 2000, 14, 941-950.

16. Remm, J. and Lohmus, A., Tree cavities in forests - the broad distribution pattern of a keystone structure for biodiversity. Forest Ecol. Manage., 2011, 262, 579-585.

17. Regnery, B., Paillet, Y., Couvet, D. and Kerbiriou, C., Which factors influence the occurrence and density of tree microhabitats in Mediterranean oak forests? Forest Ecol. Manage., 2013, 295, 118-125.

18. Martin, K., Aitken, K. and Wiebe, K., Nest sites and nest webs for cavity-nesting communities in interior British Columbia, Canada: nest characteristics and niche partitioning. The Condor, 2004, 106, 5-19.

19. Gibbons, P. and Lindenmayer, D., Tree Hollows and Wildlife Conservation in Australia, CSIRO Publishing, Melbourne, Australia, 2002, p. 230.

20. Czeszczewik, D., Walankiewicz, W. and Stansk, M., Small mammals in nests of cavity-nesting birds: why should ornithologists study rodents ? Can. J. Zool., 2008, 86, 286-293.

21. Aitken, K., Wiebe, K. and Martin, K., Nest-site reuse patterns for a cavity-nesting bird community in interior British Columbia. The Auk, 2002, 119, 391-402.

22. Biju, S. D., Senevirathne, G., Garg, S. and Mahony, S., Frankixalus, a new Rhacophorid genus of tree hole breeding frogs with oophagous tadpoles. PLoS ONE, 2016, 11, e0145727.

23. Duengkae, P. and Chuaynkern, Y., Observations of basking in Varanus bengalensis nebulosus from northeastern Thailand. Biawak, 2009, 3, 88-92.

24. Kitching, R., Food Webs and Container Habitats: The Natural History and Ecology of Phytotelmata, Cambridge University Press, Cambridge, UK, 2000, p. 431.

25. Nishad, K. and Das, K., Metazoan community composition in tree hole aquatic habitats of Silent Valley National Park and New Amarambalam Reserve Forest of the Western Ghats, India. J. Threat. Taxa, 2012, 4, 3312-3318.

26. van der Hoek, Y., Gaona, G. and Martin, K., The diversity, distribution and conservation status of the tree-cavity-nesting birds of the world. Divers. Distrib., 2017, 23, 1120-1131.

27. van der Hoek, Y., Gaona, G., Ciah, M. and Martin, K., Global relationships between tree-cavity excavators and forest bird richness. R. Soc. Open Sci., 2020, 7, 192177.

28. Cornelius, C. et al., Cavity-nesting birds in neotropical forests: cavities as a potentially limiting resource. Ornithol. Neotropical., 2008, 19, 253-268.

29. Martin, K. and Eadie, J., Nest webs: a community-wide approach to the management and conservation of cavity-nesting forest birds. Forest Ecol. Manage., 1999, 115, 243-257.

30. Blanc, L. and Walters, J., Cavity-nest webs in a longleaf pine ecosystem. The Condor, 2008, 110, 80-92.

31. Goldingay, R., Characteristics of tree hollows used by Australian birds and bats. Wildl. Res., 2009, 36, 394-409.

32. Goldingay, R., Characteristics of tree hollows used by Australian arboreal and scansorial mammals. Aust. J. Zool., 2011, 59, 277-294.

33. Boyle, W. A., Ganong, C. N., Clark, D. B. and Hast, M. A., Density, distribution, and attributes of tree cavities in an old-growth tropical rain forest. Biotropica, 2008, 40, 241-245.

34. Gibbs, J., Hunter, M. and Melvin, S., Snag availability and communities of cavity nesting birds in tropical versus temperate forests. Biotropica, 1993, 25, 236-241.

35. Panicker, K., Ecology of hole nesting birds. J. Bombay Nat. Hist. Soc., 1980, 75, 1227-1237.

36. Thiyagesan, K., Ecology of cavity nesting birds in and around Mayiladuturai, Tamil Nadu, South India. Ph D thesis submitted to Bharathidasan University, Tamil Nadu, India, 1991, p. 140 .

37. Santharam, V., Nesting ecology of sympatric woodpeckers of the Western Ghats, India. J. Bombay Nat. Hist. Soc., 2006, 103, 202.

38. Yahya, H. S. A., Biology of Indian Barbets, Authorspress, New Delhi, India, 2001, p. 170.

39. Varghese, A. P., Ecology and behaviour of Malabar Trogon, Harpactes fasciatus malabaricus. Ph D thesis, Mahatma Gandhi University, Kottayam, India, 2002, p. 149.

40. Mudappa, D., Eight years monitoring of Malabar Grey Hornbill Ocyceros griseus nest cavity use and dynamics in the Anamalai rainforest, India. In The Third International Hornbill Workshop, Pimdee Karnpim Co. Ltd, Hornbill Research Foundation, Mahidol University, Bangkok, 2005, pp. 3-9.

41. Ishtiaq, F. and Rahmani, A., The Forest owlet Heteroglaux blewitti: vocalization, breeding biology and conservation. Ibis, 2005, 147, 197-205.

42. Balakrishnan, P., Recent sightings and habitat characteristics of the endemic Nilgiri Marten Martes gwatkinsii in Western Ghats, India. Small Carniv. Conserv., 2005, 33, 14-16.

43. Mudappa, D., Day-bed choice by the Brown Palm Civet (Paradoxurus jerdoni) in the Western Ghats. Mamm. Biol., 2006, 71, 238-243.

44. Jayson, E., Status, distribution, food and feeding of Malabar Spiny Dormouse (Platacanthomys lasiurus Blyth) in the Western Ghats of Kerala, Kerala Forest Research Institute, Research Report 293, 2006, p. 119.

45. Rajamani, N. and Sinha, A., Disconnected canopies and flying squirrels presence in a landscape matrix in the Anamalai Hills, Western Ghats. In Forest Canopies of South Asia - A Glimpse (eds Devi, S., Ganesh, T. and Tripathy, A.), ATREE, Bengaluru, India, 2012.

46. IUCN, IUCN Red List of Threatened Species, 2018; https://www. iucnredlist.org/

47. Larsson, J., Eulerr: Area-Proportional Euler and Venn Diagrams with Ellipses. R package version 6.1.0, 2020; https://cran.r-project.org/package=eulerr

48. Gu, Z., Complex heatmaps reveal patterns and correlations in multidimensional genomic data, 2016; https://doi.org/10.1093/bioinformatics/btw313

49. Fleming, R., Notes on the nest and behaviour of the Yellowbrowed Titmouse, Parus modestus (Burton). J. Bombay Nat. Hist. Soc., 1973, 70, 326-329.

50. Santharam, V., Apartment nest of the Pygmy Woodpecker Picoides nanus. J. Bombay Nat. Hist. Soc., 1999, 96, 143.

51. Santharam, V., Woodpecker holes used for nesting by secondary cavity-nesters in the Western Ghats, India. J. Bombay Nat. Hist. Soc., 2004, 101, 157-158.

52. Aubry, K. and Raley, C., The Pileated Woodpecker as a keystone habitat modifier in the Pacific Northwest. USDA For. Serv. Gen. Tech. Rep., 2002, 181, 257-274.

53. Segura, A., How does vegetation structure influence woodpeckers and secondary cavity nesting birds in African cork oak forest? Acta Oecol., 2017, 83, 22-28.

54. Barve, S. and Mason, N., Interspecific competition affects evolutionary links between cavity nesting, migration and clutch size in Old World Flycatchers (Muscicapdae). Ibis, 2015, 157, 299311.

55. Raman, T. and Mudappa, D., Correlates of hornbill distribution and abundance in rainforest fragments in the southern Western Ghats, India. Bird Conserv. Int., 2003, 13, 199-212.

56. Marsden, S. and Pilgrim, J., Factors influencing the abundance of parrots and hornbills in pristine and disturbed forests on New Britain, PNG. Ibis, 2003, 145, 45-53.

57. ENVIS, Endemic Birds of India 2018. ENVIS Resource Partner on Avian Ecology, 2018; https://bnhsenvis.nic.in/Database/1_ 17700.aspx 
REVIEW ARTICLE

58. Medway, L. and Marshall, A., Roost-site selection among flatheaded bats (Tylonycteris spp.). J. Zool. London, 1970, 161, $237-$ 245 .

59. Short, L., Habits of some Asian woodpeckers (Aves, Picidae) Bull. Am. Museum Nat. Hist., 1973, 152(5), 253-364.

60. Rhodes, B., O'Donnell, C. and Jamieson, I., The roles of pre dation, microclimate, and cavity abundance in the evolution of New Zealand's tree-cavity nesting avifauna. Notornis, 2009, 56, 190-200.

61. Barnes, H., Nesting in western India. J. Bombay Nat. Hist. Soc., 1888, 3, 205-224.

62. Sathyakumar, S., Bashir, T., Bhattacharya, T. and Poudyal, K., Assessing mammal distribution and abundance in intricate eastern Himalayan habitats of Khangchendzonga, Sikkim, India. Mammalia, 2011, 75, 257-268.

63. Wilkinson, J. A. and Drewes, R. C., Character assessment, genus level boundaries, and phylogenetic analyses of the family Rhacophoridae : a review and present day status. Contemp. Herpetol. 2000, 2, 1-24.

64. Tikader, B. and Sharma, R., Handbook: Indian Lizards, Zoological Survey of India (ZSI), 1992, p. Xv + 250 .

65. Ali, S. and Ripley, S., Compact Handbook of the Birds of India and Pakistan, Oxford University Press, Oxford, UK, 1987, p. 841.

66. Grimmett, R., Inskipp, C. and Inskipp, T., Birds of the Indian Sub continent: India, Pakistan, Sri Lanka, Nepal, Bhutan, Bangladesh and the Maldives, Bloomsbury Publishing, India, 2013, p. 528.

67. Kala, H., Assessment of the population of White-naped tit (Parus nuchalis) and its thorn forest habitat in southern Aravalli Hills, Rajasthan, India. Research Report, Rufford Small Grants Foundation, 2011; https://ruffordorg.s3.amazonaws.com/media/project_ reports/11.10.09\%20Final\%20Report.pdf (accessed on 14 December 2017)

68. Sayyed, A., Pyron, R. and Dahanukar, N., Cnemaspis flaviventralis, a new species of gecko (Squamata: Gekkonidae) from the Western Ghats of Maharashtra, India. J. Threat. Taxa, 2016, 8, 9619-9629.

69. Gupta, D. P. and Sinha, A. K., Notes on the burrows of Varanus bengalensis in and around Agra. Zoos Print J., 2001, 16, 651-654.

70. Das, A., Basu, D., Converse, L. and Suresh, C., Herpetofauna of Katerniaghat Wildlife Sanctuary, Uttar Pradesh, India. J. Threat. Taxa, 2012, 4, 2553-2568.

71. Jackson, J. and Jackson, B., Ecological relationships between fungi and woodpecker cavity sites. The Condor, 2004, 106, 37-49.

72. Richter, C., Wood characteristics: description, causes, prevention, impact on use and technological adaptation. Springer Internationa
Publishing, New York, USA, 2014; https://doi.org/10.1007/978-3319-07422-1.

73. van Geffen, K., Poorter, L., Sass-Klaassen, U., Van Logtestijn, R. and Cornelissen, J., The trait contribution to wood decomposition rates of 15 Neotropical tree species. Ecology, 2010, 91, 36863697.

74. Chandramouli, S. and Ganesh, S., Herpetofauna of southern Western Ghats, India - reinvestigated after decades. Taprobanica, 2010, 2, 72-85.

75. Das, A., Diversity and distribution of herpetofauna and evaluation conservation status in Barail Hill Range (including Barail wildlife sanctuary), Assam, Northeast India. Research Report, Rufford Small Grants Foundation, Aranyak, Assam, 2008, p. 60; https:// ruffordorg.s3.amazonaws.com/media/project_reports/28.03.06\%20Detailed\%20Final\%20Report.pdf (accessed on 15 December 2017).

76. Chandramouli, S., Vasudevan, K., Harikrishnan, S., Dutta, S., Janani, J., Sharma, R., Das, and Aggarwal, R., A new genus and species of arboreal toad with phytotelmonous larvae, from the Andaman Islands, India (Lissamphibia, Anura, Bufonidae). ZooKeys, 2016, 555, 57-90.

77. James, D. and Kannan, R., Nesting habitat of the Great Hornbill (Buceros bicornis) in the Anamalai Hills of southern India Wilson J. Ornithol., 2009, 121, 485-492.

78. Bachan, K. and Kannan, R., Understanding species-habitat relationship and role of ethnic communities in conservation and management of Hornbills and their habitat, Anamalai's (Parambikulam Tiger Reserve) Southern Western Ghats. In Proceedings of the 1st Indian Biodiversity Congress, Centre for Innovation in Science and Social Action (CISSA), Thiruvananthapuram, Kerala, 2010.

79. Lindenmayer, D. et al., New policies for old trees: averting a global crisis in a keystone ecological structure. Conserv. Lett. 2014, 7, 61-69.

ACKNOWLEDGEMENTS. The present study was conducted as part of a project funded by Ministry of Environment, Forest and Climate Change, Govt of India. We thank the authorities of JNTBGRI, Thiruvananthapuram and KFRI, Thrissur, Dr T. S. Nayar, S. Suresh and Dr T. N. Bindu for their inputs and support.

Received 26 August 2020; revised accepted 21 June 2021

doi: $10.18520 / \mathrm{cs} / \mathrm{v} 121 / \mathrm{i} 4 / 490-501$ 